\title{
Editorial
}

\section{Influencia de los cambios ambientales en el riesgo y el aumento de nuevas pandemias}

\author{
El aumento de la temperatura amenazará nuestra existencia \\ sobre este planeta. Nuestros informes indican que los \\ impactos del calentamiento son mucho más graves de lo \\ que pensábamos antes. Hoesung Lee (Intergovernmental \\ Panel on Climate Change-IPCC)
}

La civilización actual es el fruto de la estabilidad ambiental del planeta desde la última glaciación. La imperante consistencia climática permitió en algunas culturas la transición de ser recolectores y cazadores a agricultores y, así, una especie con menos de 6 millones de individuos se convirtió rápidamente en una ultrasocial (Gowdy \& Krall, 2014) que hoy supera los 7 mil millones de habitantes en la actualidad. El nuevo equilibrio permitió la domesticación de plantas y animales en todos los continentes y la formación de asentamientos permanentes, además, cesaron los cambios en el nivel del mar y el hombre pudo establecerse también en las costas (Benjamin, et al., 2017). El hombre empezó a vivir bajo la premisa de un ambiente y un clima predecibles, tanto así que se hizo vulnerable a los cambios y algunas de las grandes civilizaciones de la antigüedad, por ejemplo, la maya, sucumbieron ante las esporádicas anomalías térmicas que llevaron a largos períodos de sequía (Kennett, et al., 2012). Esa estabilidad ambiental que tanto nos ha permitido a los humanos está llegando a su fin.

La huella que el crecimiento de Homo sapiens ha dejado en el planeta, hasta convertirse en una especie ultrasocial, excede sus límites (Rockström, et al., 2009). Pese a ello, la gran preocupación actual es el incremento en la cantidad de dióxido de carbono $\left(\mathrm{CO}_{2}\right)$ atmosférico, un gas con efecto invernadero y consecuencias en el clima de la tierra. La masificación de los combustibles de origen fósil a partir de la revolución industrial marcó el inicio de una cadena de efectos en el ambiente. El problema radica en que, en menos de dos siglos, hemos liberado a la atmósfera el $\mathrm{CO}_{2}$ que se acumuló por medio de la fotosíntesis a lo largo de varias épocas geológicas (Mondragón, 2021), aunque en este sentido debo aclarar que no solamente los combustibles son los responsables de tales emisiones, también lo es la industrialización de la agricultura y de la ganadería para responder a las demandas de una población creciente (Röös, et al., 2017).

Hoy se tolera como un mal necesario la destrucción de la biodiversidad para convertir tierras en zonas agrícolas que aseguren el crecimiento económico, y se acepta que esto puede compensarse con la tecnología indicada o alguna innovación económica (Lafuite, et al., 2017; Lafuite \& Loreau, 2017). Infortunadamente, los servicios ecosistémicos que nos brinda la biodiversidad, como la depuración del agua y el aire, el reciclaje de nutrientes, la polinización, y el control de enfermedades y plagas, entre otros, se verán profundamente afectados antes de que la humanidad llegue a los 11 mil millones de habitantes proyectados para el 2100 (Henderson \& Loreau, 2018). Se asume que el desarrollo agropecuario es el motor del crecimiento demográfico, pero en los modelos poblacionales humanos la biodiversidad y los servicios ecosistémicos son igualmente necesarios para la supervivencia (Henderson \& Loreau, 2019; Lafuite \& Loreau, 2017). En todo caso, la degradación ambiental se retroalimenta con el cambio climático.

Las anomalías climáticas que producen olas de calor, sequías o inundaciones se manifiestan ahora todos los años en diferentes lugares del mundo (IPCC, 2021). Desde el 2005 las tormentas tropicales han aumentado en frecuencia e intensidad (Eakin, et al., 2010), y 
el 2020 fue el año récord por el número de huracanes en el Atlántico. Además, las técnicas insostenibles en la minería, la ganadería y la agricultura, además del inapropiado manejo de las aguas, incluida la canalización de los ríos y el relleno de los humedales, así como las aguas residuales deficientemente tratadas, están aislando a las especies silvestres en ecosistemas empobrecidos y fragmentados, cada vez más cercanos a las viviendas humanas (Rohr, et al., 2019). En Colombia, por ejemplo, después de la firma del tratado de paz con las guerrillas en el 2016, el fuego aumentó en un 52 \% en las zonas de reserva (Armenteras, et al., 2019), que se cuentan entre los pocos lugares donde se espera que se conserven los ecosistemas naturales. Al cambiar la gobernabilidad en los territorios del país (Salazar, 2019), se disparó la deforestación (Graesser, et al., 2015). En uno de los tres países más biodiversos del planeta, los ecosistemas más importantes se están convirtiendo en sabanas para la ganadería extensiva (Franco, et al., 2019). Las condiciones que fomentan el contacto entre el hombre y los animales silvestres están en aumento, y lo que es más preocupante, tal como ocurre con el cambio climático, no parece posible prevenir esta situación.

Cuanto más crece nuestra población, mayor será la presión de la selección natural. ¿Cómo? Estamos aún en la pandemia del virus SARS-CoV-2, el llamado COVID-19, la cual fue el producto de una zoonosis debida a la transmisión de un agente infeccioso de un animal a los humanos. Debido a la deforestación, la fragmentación de los ecosistemas naturales y el cambio climático, varias enfermedades infecciosas y parásitos exclusivos de ecosistemas naturales entran en contacto con el hombre directamente o a través de sus animales domésticos (Borremans, et al., 2019). Los cambios en las técnicas agropecuarias y la caza en cercanías a los entornos silvestres han sido los responsables de, por lo menos, 300 enfermedades nuevas desde 1940 (Keesing, et al., 2010). El riesgo de un desborde zoonótico es mayor en bosques alterados y fragmentados. Los arbovirus, o virus con un vector artrópodo, suman al menos 30 infecciones patógenas, entre ellas el chikunguña, el dengue, la fiebre amarilla y el Zika. El vector principal es el mosquito de origen africano Aedes aegypti (Souza-Neto, et al., 2019), pero lo preocupante es el aumento de los animales intermediarios de los virus, que, en el caso del Zika, incluyen cabras, ovejas, caballos, vacas, patos, ratas, murciélagos, orangutanes y búfalos (Vorou, 2016).

El cambio climático y la alteración de los ciclos naturales son factores que aumentan el riesgo de epidemias en los humanos. El sistema inmunológico de los animales silvestres hospederos de virus se ve comprometido al enfrentar hambrunas, estrés térmico o sequías. Un Henipavirus conocido como Hendra $(\mathrm{HeV})$, por ejemplo, es el responsable de una grave enfermedad que se descubrió a finales del siglo XX en Australia, cuya mortalidad fue del $70 \%$ en humanos. Pese a que han sido pocos los brotes de este virus, coincidieron con la escasez de alimento de los zorros voladores (murciélagos), hospederos del virus, en sus ecosistemas de origen. Al escasear el néctar de flores de Eucaliptus, principal fuente de alimento de estos murciélagos, se vieron en la necesidad de entrar a zonas rurales en donde se produjo el desborde zoonótico hacia el hombre a través de los caballos. Epidemias como la de Hendra se han podido anticipar mediante el modelamiento del clima, cuyas anomalías alteran los ciclos de floración de los eucaliptos (Martin, et al., 2018), de manera que el estrés ambiental y fisiológico al que se vieron sometidos, alteró el sistema inmunológico de los zorros voladores y fomentó la replicación viral en números elevados, aumentándose aún más el riesgo de desborde zoonótico (McMichael, et al., 2017). Los cambios en el sistema inmunológico de los murciélagos pteropodidos se han correlacionado con alteraciones ambientales y el desborde zoonótico de los virus Hendra y Nipah (NiV), capaces de inducir peligrosas pandemias (Kessler, et al., 2018; McMichael, et al., 2017). La expansión de la especie humana nos expondrá a más enfermedades infecciosas.

Podemos concluir que la alteración de los diferentes componentes del ambiente aumenta el riesgo de desborde zoonótico y de nuevas epidemias. En la figura 1 se detalla el circulo vicioso entre el crecimiento humano insostenible y la alteración de la estabilidad ambiental. Esta situación nos acerca al contacto con los animales y los vectores que son portadores de enfermedades infecciosas potenciales para los humanos. Las alteraciones ambientales, y el estrés asociado, reducen la capacidad inmunológica de todo el sistema y, por ende, 


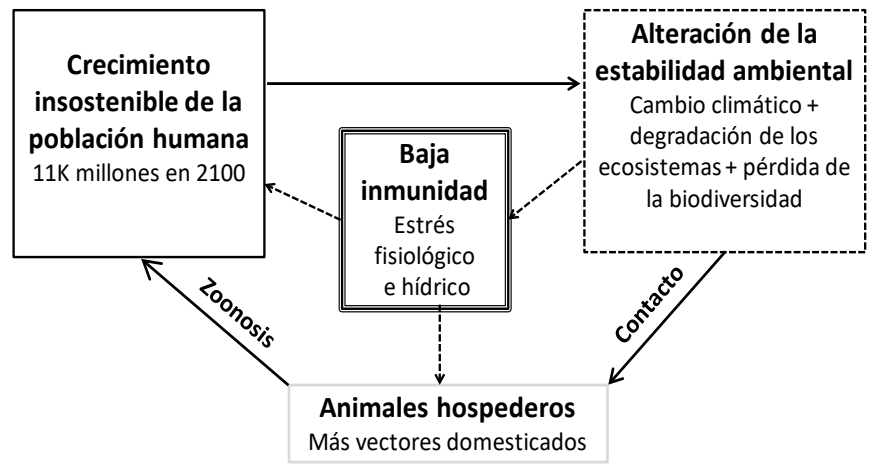

Figura 1. Aumento del riesgo de desborde zoonótico de enfermedades infecciosas emergentes debido a la retroalimentación entre el crecimiento poblacional insostenible y la alteración de la estabilidad ambiental

aumentan las probabilidades del desborde zoonótico. Al desaparecer las barreras entre estos animales y el hombre en ambientes alterados que fomentan el estrés animal, aumentará el riesgo de contagio y de nuevas pandemias (Kessler, et al., 2018; Plowright, et al., 2017).

Son ya muchas las evidencias de los efectos negativos -algunos quizás irreversiblesdel cambio climático y la degradación de la biodiversidad en nuestro bienestar y economía; debemos actuar de forma decisiva inmediatamente. Es imperativo reducir las emisiones de gases de efecto invernadero mediante una transformación energética y detener la degradación de los ecosistemas naturales. Todavía estamos viviendo las consecuencias de una pandemia, una circunstancia que puede volverse más frecuente si no actuamos ya y cuyos efectos serán más graves si hacen sinergia con una eventual crisis climática global.

Juan Armando Sánchez, Ph.D.

Profesor titular, Departamento de Ciencias Biológicas, Universidad de los Andes, Bogotá, Colombia

@ biommar

\section{Referencias}

Armenteras, D., Schneider, L., Dávalos, L. M. (2019). Fires in protected areas reveal unforeseen costs of Colombian peace. Nature Ecology \& Evolution. 3 (1): 20-23. Doi: 10.1038/s41559018-0727-8

Benjamin, J., Rovere, A., Fontana, A., Furlani, S., Vacchi, M., Inglis, R. H., Gehrels, R. (2017). Late Quaternary sea-level changes and early human societies in the central and eastern Mediterranean Basin: An interdisciplinary review. Quaternary International. 449: 29-57. Doi: 10.1016/j.quaint.2017.06.025

Borremans, B., Faust, C., Manlove, K. R., Sokolow, S. H., Lloyd-Smith, J. O. (2019). Crossspecies pathogen spillover across ecosystem boundaries: Mechanisms and theory. Philosophical Transactions of the Royal Society B: Biological Sciences. 374 (1782): 20180344. Doi: 10.1098/rstb.2018.0344

Eakin, C. M., Morgan, J. A., Heron, S. F., Smith, T. B., Liu, G., Alvarez-Filip, L., Bouchon, C. (2010). Caribbean corals in crisis: Record thermal stress, bleaching, and mortality in 2005. PloS one. 5 (11): e13969.

Franco, A. L. C., Sobral, B. W., Silva, A. L. C., Wall, D. H. (2019). Amazonian deforestation and soil biodiversity. Conservation Biology. 33 (3): 590-600. Doi: 10.1111/cobi.13234

Gowdy, J. \& Krall, L. (2014). Agriculture as a major evolutionary transition to human ultrasociality. Journal of Bioeconomics. 16 (2): 179-202. Doi: 10.1007/s10818-013-9156-6

Graesser, J., Aide, T. M., Grau, H. R., Ramankutty, N. (2015). Cropland/pastureland dynamics and the slowdown of deforestation in Latin America. Environmental Research Letters. 10 (3): 034017. Doi: 10.1088/1748-9326/10/3/034017

Henderson, K. \& Loreau, M. (2018). How ecological feedbacks between human population and land cover influence sustainability. PLOS Computational Biology. 14 (8): e1006389. Doi: 10.1371/journal.pcbi.1006389 
Henderson, K. \& Loreau, M. (2019). An ecological theory of changing human population dynamics. People and Nature. 1 (1): 31-43. Doi: 10.1002/pan3.8

IPCC. (2021). Climate Change 2021: The Physical Science Basis. Contribution of Working Group I to the Sixth Assessment Report of the Intergovernmental Panel on Climate Change. MassonDelmotte, V., P. Zhai, A. Pirani, S. L. Connors, C. Péan, S. Berger, N. Caud, Y. Chen, L. Goldfarb, M. I. Gomis, M. Huang, K. Leitzell, E. Lonnoy, J. B. R. Matthews, T. K. Maycock, T. Waterfield, O. Yelekçi, R. Yu and B. Zhou (eds.). Cambridge University Press. En prensa

Keesing, F., Belden, L. K., Daszak, P., Dobson, A., Harvell, C. D., Holt, R. D., Ostfeld, R. S. (2010). Impacts of biodiversity on the emergence and transmission of infectious diseases. Nature. 468 (7324): 647-652. Doi: 10.1038/nature09575

Kennett, D. J., Breitenbach, S. F. M., Aquino, V. V., Asmerom, Y., Awe, J., Baldini, J. U. L., Haug, G. H. (2012). Development and Disintegration of Maya Political Systems in Response to Climate Change. Science. 338 (6108): 788-791. Doi: 10.1126/science.1226299

Kessler, M. K., Becker, D. J., Peel, A. J., Justice, N. V., Lunn, T., Crowley, D. E., Plowright, R. K. (2018). Changing resource landscapes and spillover of henipaviruses. Annals of the New York Academy of Sciences. 1429 (1): 78-99. Doi: 10.1111/nyas.13910

Lafuite, A.-S., de Mazancourt, C., Loreau, M. (2017). Delayed behavioural shifts undermine the sustainability of social-ecological systems. Proceedings of the Royal Society B: Biological Sciences. 284 (1868): 20171192. Doi: 10.1098/rspb.2017.1192

Lafuite, A.-S. \& Loreau, M. (2017). Time-delayed biodiversity feedbacks and the sustainability of social-ecological systems. Ecological Modelling. 351: 96-108. Doi: 10.1016/j.ecolmodel. 2017.02.022

Martin, G., Yáñez-Arenas, C., Plowright, R. K., Chen, C., Roberts, B., Skerratt, L. F. (2018). Hendra Virus Spillover is a Bimodal System Driven by Climatic Factors. EcoHealth. 15 (3): 526-542. Doi: 10.1007/s10393-017-1309-y

McMichael, L., Edson, D., Smith, C., Mayer, D., Smith, I., Kopp, S., Field, H. (2017). Physiological stress and Hendra virus in flying-foxes (Pteropus spp.), Australia. PLoS ONE. 12 (8). Doi: 10.1371/journal.pone.0182171

Mondragón, F. (2021) Ciclos del dióxido de carbono en la formación y utilización de combustibles fósiles y su efecto en el cambio climático. Rev. Acad. Colomb. Cienc. Ex. Fis. Nat. Doi: https://doi.org/10.18257/raccefyn.1364

Plowright, R. K., Parrish, C. R., McCallum, H., Hudson, P. J., Ko, A. I., Graham, A. L., LloydSmith, J. O. (2017). Pathways to zoonotic spillover. Nature Reviews Microbiology. 15 (8): 502-510. Doi: 10.1038/nrmicro.2017.45

Rockström, J., Steffen, W., Noone, K., Persson, Å., Chapin, F. S., Lambin, E. F., Foley, J. A. (2009). A safe operating space for humanity. Nature. 461 (7263): 472-475. Doi: 10.1038/461472a

Rohr, J. R., Barrett, C. B., Civitello, D. J., Craft, M. E., Delius, B., DeLeo, G. A., Tilman, D. (2019). Emerging human infectious diseases and the links to global food production. Nature Sustainability. 2 (6): 445-456. Doi: 10.1038/s41893-019-0293-3

Röös, E., Bajželj, B., Smith, P., Patel, M., Little, D., Garnett, T. (2017). Greedy or needy? Land use and climate impacts of food in 2050 under different livestock futures. Global Environmental Change. 47: 1-12. Doi: 10.1016/j.gloenvcha.2017.09.001

Salazar, F. Z. (2019). FARC and Deforestation in Colombia: A Case for Rebel Governance? Georgetown University. 31 pp.

Souza-Neto, J. A., Powell, J. R., Bonizzoni, M. (2019). Aedes aegypti vector competence studies: A review. Infection, Genetics and Evolution. 67: 191-209. doi: 10.1016/j.meegid.2018.11.009

Vorou, R. (2016). Zika virus, vectors, reservoirs, amplifying hosts, and their potential to spread worldwide: What we know and what we should investigate urgently. International Journal of Infectious Diseases. 48: 85-90. doi: 10.1016/j.ijid.2016.05.014 